\title{
Pessoa com deficiência entre o modelo biomédico e o modelo biopsicossocial: concepções em disputa
}

\section{Person with disabilities between the biomedical model and the biopsychosocial model: conceptions in dispute}

\author{
Vitor Hugo Bueno Fogaça* \\ Marcos Antonio Klazura**
}

\begin{abstract}
Resumo: 0 artigo aborda conceitos em disputa sobre pessoa com deficiência, a partir de uma análise entre o modelo biomédico e biopsicossocial. Trata-se de discutir concepções que incidem diretamente nas políticas públicas para esse segmento. Entendendo que as políticas públicas são resultado das disputas de interesses econômicos, das forças sociais e das ações governamentais. Sendo assim, é neste cenário que se busca garantir a defesa do acesso as políticas públicas para as pessoas com deficiência. 0 ensaio tem o objetivo de analisar o modelo biopsicossocial da Lei Brasileira de Inclusão de 2015, no contexto de disputa com o modelo biomédico, levando em consideração as categorias: barreiras, impedimentos, participação e a igualdade de condições. A problemática debatida se apresenta na investigação da aplicabilidade do modelo biopsicossocial nas políticas públicas destinadas as pessoas com deficiência. $\mathrm{O}$ artigo foi elaborado com o método crítico dialético, a partir de uma pesquisa bibliográfica e as suas principais considerações resultam na defesa do modelo biopsicossocial das políticas públicas que assegurem a dignidade humana das pessoas com deficiência reconhecendo-as como sujeitos sociais de direitos.
\end{abstract}

Palavras-chaves: Pessoa com deficiência. Políticas Públicas. Modelo Biopsicossocial.

\begin{abstract}
This article discusses concepts in dispute about people with disabilities, based on an analysis of the biomedical and biopsychosocial model. It is about discussing conceptions that directly affect public policies for this segment. Understanding that public policies are the result of disputes of
\end{abstract}

\footnotetext{
* Doutor e mestre em Ciências Sociais Aplicadas pela Universidade Estadual de Ponta Grossa - UEPG. Professor colaborador Departamento de Direito das Relações Sociais da Universidade Estadual de Ponta Grossa. E-mail: vitorbueno0602@hotmail. com.

** Mestre em Direitos Humanos e Políticas Públicas. Professor do curso de Serviço Social no Centro Universitário Internacional - UNINTER .E-mail: marcosklazura@gmail.com.
} 
economic interests, social forces and governmental actions. Thus, it is in this scenario that it seeks to ensure the defense of access to public policies for people with disabilities. The essay aims to analyze the biopsychosocial model of the Brazilian law of inclusion of 2015 , in the context of dispute with the biomedical model, taking into account the categories: barriers, impediments, participation and equal conditions. The debated problem is presented in the investigation of the applicability of the biopsychosocial model in public policies aimed at people with disabilities. The article was elaborated with the dialectical critical method, based on a bibliographic research and its main considerations result in the defense of the biopsychosocial model of public policies that ensure the human dignity of people with disabilities Recognizing them as social subjects of rights.

Key words: Person with disabilities. Public policies. Biopsychosocial model.

Recebido em 11/03/2019. Aceito em 08/02/2021

\section{Introdução}

O presente artigo apresenta a discussão sobre o conceito de pessoa com deficiência no contexto das disputas entre o modelo biomédico e o modelo biopsicossocial.

Buscou-se explicitar a concepção contemporânea de pessoa com deficiência a partir da Convenção Internacional sobre os Direitos das Pessoas com Deficiência da ONU de 2006 inscrita na Lei Brasileira de Inclusão de 2015. Há relevância nesta explanação, pois é a partir desta concepção que as políticas públicas devem ser desenvolvidas para este segmento.

Sabe-se que as políticas públicas se estabelecem no contexto das lutas sociais e das disputas de interesses. Historicamente as políticas públicas destinadas as pessoas com deficiência foram embasadas pelo modelo biomédico de concepção de deficiência.

Neste sentido, o modelo biopsicossocial vem como a melhor alternativa, visto que, considera para além da patologia corporal os fatores socioambientais, psicológicos e pessoais. Sendo assim, o problema apresentado consiste na indagação: como o modelo biopsicossocial pode ser aplicado nas políticas públicas destinada a pessoa com deficiência?

O objetivo geral desse artigo incide na discussão do modelo biopsicossocial da Lei Brasileira de Inclusão (LBI) em meio às disputas com o modelo biomédico.

Sendo assim, os objetivos específicos perpassam pelo debate das categorias: barreiras, impedimentos, participação e igualdade de condições no bojo da sociedade capitalista, trazendo a análise de como o modelo biopsicossocial da LBI pode ser aplicado nas políticas públicas para pessoas com deficiência.

Justifica-se que a temática é uma abordagem pouco explorada nas produções acadêmicas, especialmente por se tratar de disputas que ainda se fazem presentes nos dias atuais, não havendo uma pacificação acerca dos caminhos oficialmente adotados pelo poder público. Ainda, a produção 
se fundamenta na necessidade de defesa da dignidade humana das pessoas com deficiência, tema em consonância com a luta pela efetivação dos direitos humanos e das políticas públicas.

$\mathrm{O}$ artigo foi elaborado a partir de uma pesquisa exploratória com abordagem qualitativa, tendo como instrumento de coleta de dados a pesquisa bibliográfica. Para isso, utilizou-se do método crítico dialético, tendo em vistas a contradição, a historicidade e a totalidade dos processos.

Faz-se necessário frisar, inicialmente, que a opção por uma abordagem crítico dialética se justifica na medida em que procurou-se apresentar, ainda que de forma inicial, a discussão nas últimas décadas sobre as disputas entre o modelo biomédico e biopsicossocial da concepção de deficiência.

Conforme restará apresentado, tal embate não se dá apenas em termos exclusivamente terminológicos, mas acerca da própria concepção dos papeis da pessoa com deficiência na sociedade, bem como do modo como ela é inserida nas políticas públicas implementadas.

Assim, é possível verificar-se posicionamentos frontalmente opostos, os quais se contrapuseram nas últimas décadas, notadamente por meio de lutas e embates sociais, o que acabou por se viabilizar alguns avanços que merecem ser considerados a partir dessa construção de oposições vivenciadas pelas pessoas com deficiência no país.

\section{Considerações gerais sobre a pessoa com deficiência: aproximações terminológicas}

Inicia-se o debate deste artigo destacando que as concepções sobre as Pessoas com deficiência foram se alterando no percurso da história, não de forma linear, mas a partir das lutas e das permanentes disputas de projetos societários. Neste sentido, o debate desse tema pressupõe um caminho que perpassa pela luta por reconhecimento de direitos, na linha entre exclusão e inclusão social, sem desconsiderar o histórico de violação de direitos humanos, da segregação, institucionalização, pela discussão do padrão de normalidade e possibilidades de inclusão.

Ao se analisar historicamente as nomenclaturas correspondentes à deficiência percebe-se que estes são definidos a partir dos valores da sociedade em cada época. A nomenclatura está carregada de significado, este pode ser de respeito ou discriminação. (SASSAKI, 2003). Por isso, mais do que uma adequação das terminologias, as nomenclaturas representam concepções sobre determinados assuntos, neste caso sobre as pessoas com deficiência. Assim, "longe de ser irrelevante, a forma como perspectivamos a deficiência é essencial na forma como definimos os problemas e delineamos as soluções". (MARTINS et al., 2012, p.48)

Para destacarmos algumas concepções sobre as pessoas com deficiência é necessário inicialmente rememorar que a sociedade se constituiu por uma "normalização", um padrão estabelecido, aqueles que não se encontravam nesses critérios automaticamente eram excluídos. Neste cenário é que se encontram as pessoas com deficiência, por isso da necessidade de evidenciar as barreiras impostas e trabalhar na perspectiva de sua redução, promovendo o respeito à diversidade humana, conceito que corresponde ao conjunto de diferenças e particularidades que compõem o rol da pluralidade presente na sociedade. (PARANA, 2016)

Historicamente as pessoas com deficiência enfrentaram muitas adversidades, em alguns povos como os bárbaros nômades, os espartanos e os romanos, entre outros, "eliminavam as crianças com deficiência em rituais religiosos ou com apoio legal, conforme previa a própria lei romana das XII Tábuas". (FONSECA, 2012, p.51). Na Idade Média a deficiência passa ser compreendida como fruto do pecado, como castigo divino, é nesse momento da história que se difunde a 
ideia do isolamento social das pessoas com deficiência em instituições beneficentes, fortalecendo a segregação e exclusão social das pessoas com deficiência. (FONSECA, 2012)

A partir do século XVII iniciam-se métodos de aprendizagem, mas essas mudanças aconteceram de forma diferenciada variando por localidades. 0 modelo econômico também é determinante na concepção de pessoa com deficiência, com o advento da revolução industrial e do capitalismo a ideia de "inválido" no sentido de inútil, sem valor ao mercado, sujeito improdutivo é empregado as pessoas com deficiência. (PARANA, 2016)

A partir de eventos históricos como, por exemplo, a I e II Guerra Mundial comparece a terminologia "incapacitado" referindo as pessoas que adquiriram sequelas devido aos conflitos, desenvolvem-se então, programas de reabilitação. Ainda, outros termos como "defeituosos" para se referir aos deficientes físicos e "excepcionais" para as pessoas com deficiência mental, exaltando a diferença no sentido negativo. Destaca-se que é por volta da década de 1950 que surgem no Brasil as instituições de atendimento específico a esse grupo. E ainda, na década de 1960 se realizaram os primeiros jogos paraolímpicos. (PARANA, 2016)

Um marco da luta pelos direitos das pessoas com deficiência foi a instituição em 1981 do “Ano Internacional das Pessoas Deficientes" pela Organização das Nações Unidas (ONU), devido às pressões dos movimentos sociais que atuavam nesse segmento. Desse modo, foi a primeira vez que se utilizou o termo "pessoa" o que contribuiu para ressignificar a imagem da Pessoa com deficiência. Este fato é considerado como marco inicial que fortaleceu a luta pela igualdade com as demais pessoas, com e sem deficiência. (SASSAKI, 2002). Vale destacar que esse processo de reconhecimento não é automático, mas há um indicativo de uma mudança cultural, em construção ainda, que busca equiparação dos direitos e igualdade de condições.

O termo "pessoa deficiente" passa a ser disputado com críticas no sentido de a deficiência estar em toda a pessoa, assim especialmente em países de língua portuguesa no final da década de 1980 e inicio dos anos 1990, passa-se a utilizar a nomenclatura "pessoas portadoras de deficiência" ou simplesmente "portadores de deficiência", até aquele momento compreendido como um detalhe da pessoa. (SASSAKI, 2002). Esse termo passa a ser incorporado nos nomes das instituições que atuam com esse público e está presente em legislações deste período. No entanto, também recebe críticas, pois portador é aquele que leva, carrega alguma coisa e pode deixar de portar, já a deficiência é uma condição inata ou adquirida da pessoa.

Ainda, na década de 1990 fortalece-se o termo "necessidades especiais", "portadores de necessidades especiais" e "pessoa especial" na tentativa de amenizar a deficiência. Termo que não contribuiu para o reconhecimento enquanto sujeitos de direitos e da importância da luta pela autonomia, levando em consideração o grau da deficiência. (PARANA, 2016). Destaca-se que esta terminologia ainda se apresenta no vocabulário da população.

É possível já se verificar uma dialeticidade dos embates terminológicos apresentados durante esse breve percurso histórico, na medida em que tais construções não se deram de maneira neutra, mas baseadas nos discursos oficiais e nas lutas por garantias de direitos.

Foi na Declaração de Salamanca de 1994, resolução da ONU sobre educação inclusiva que o termo "Pessoa com deficiência" foi utilizado em uma legislação pela primeira vez. Assim, a terminologia ganha cada vez mais adeptos especialmente pessoas com deficiência, o termo vincula a ideia de empoderamento, da possibilidade de fazer escolhas e tomar decisões e de outro lado não camuflar a deficiência valorizando as diferenças, fortalecendo a luta pela equiparação de oportunidades, respeitando as especificidades. (SASSAKI, 2002) 
Sabe-se que a adoção dos eufemismos para qualificar as pessoas com deficiência como, por exemplo, as expressões: pessoas portadoras de necessidades especiais, especial, incapaz, aleijados, mudinhos, inválidos, ceguinhos, etc., essas terminologias carregam o peso da exclusão social e da inferiorização dos sujeitos. Portanto, romper com essas concepções é ir além do politicamente correto, significa contribuir para a libertação dos estigmas históricos. (FONSECA, 2012)

Sendo assim, a terminologia aceita como mais adequada atualmente é Pessoa com deficiência presente na Convenção Internacional sobre os Direitos das Pessoas com Deficiência da Organização das Nações Unidas (ONU) de 2006. Destaca-se que essa escolha teve uma forte influência estadunidense, outros termos como pessoa deficiente entendido como a característica individual na interação social inicialmente foi utilizado pelos estudiosos. Há uma vertente mais crítica que utiliza apenas a terminologia deficiente para incorporar a cultura e a identidade. (DINIZ, 2007)

Vale destacar que a Convenção da ONU sobre os Direitos das Pessoas com deficiência adotou a expressão "Pessoa com deficiência" a partir do fundamento: nada a nosso respeito sem a nossa participação, o maior significado da proposta era romper com as políticas assistencialistas e tuteladoras que impunham às pessoas com deficiência um papel de coadjuvantes nas questões diretamente ligadas a elas. (FONSECA, 2012)

Segundo Diniz (2007, p.19), “a deficiência passou a ser um conceito político”. Portanto, é um conceito em disputa, no movimento da sociedade. As terminologias com conotação agressiva como: aleijado, débil mental, retardado, manco, entre outros, foram compreendidas como inadequadas, entretanto o movimento de redefinição da deficiência como Pessoa com deficiência ou deficiente é uma ação inacabada. Vale destacar que a terminologia é arraigada de valor simbólico que define a concepção da Pessoa com deficiência e por consequência influencia as políticas públicas para este segmento.

Conforme já mencionado, o conceito de pessoa com deficiência atual vem da Convenção Internacional sobre os Direitos das Pessoas com Deficiência da ONU aprovado pela Assembleia Geral em 2006, ratificado e incorporado no ordenamento jurídico brasileiro em 2009 como emenda constitucional. Conceitua:

Art. 1ํ: Pessoas com deficiência são aquelas que têm impedimento de longo prazo de natureza física, mental, intelectual ou sensorial, os quais, em interação com diversas barreiras, podem obstruir sua participação plena e efetiva na sociedade em igualdade de condições com as demais pessoas.

Fundamentada a partir da Declaração Universal dos Direitos Humanos e os Pactos internacionais de direitos humanos, a Convenção ressalta a necessidade de reconhecimento dos direitos, das liberdades das pessoas com deficiência sem qualquer distinção. Nessa perspectiva, a deficiência é entendida como o resultado da interação das pessoas com deficiência e das diversas barreiras impostas que impedem a participação plena na sociedade, em igualdade de condições com as demais pessoas. (BRASIL, 2008)

A deficiência está, doravante, nas barreiras sociais que excluem essas pessoas do acesso aos direitos humanos básicos. Trocando em miúdos, quero dizer que a deficiência não está na pessoa, e sim na sociedade, que deve, como determinam todos os demais dispositivos da Convenção da ONU, buscar políticas públicas para que os detentores daqueles atributos outrora impeditivos emancipem-se. (FONSECA, 2012, p.51) 
Desse modo, a deficiência deve ser entendida como uma característica da condição humana. Assim, as categorias presentes no conceito de Pessoa com deficiência apresentado no primeiro artigo da Convenção da ONU devem embasar a formulação das políticas públicas. Deve-se analisar criticamente o significado de interação, barreiras, participação e igualdade de condições, no contexto do sistema capitalista que expressa a desigualdade como regra. O desafio posto é efetivar políticas públicas que rompam com ações fragmentadas, mas contemplem a totalidade dos processos. Pode-se tomar como base a Convenção de Direitos Humanos de Viena de 1993, a qual afirma que os direitos são universais, indivisíveis, interdependentes e inter-relacionados. É nesta direção que as políticas públicas devem ser materializadas, considerando as particularidades e especificidades de cada grupo, sem romper com o princípio da transversalidade dos direitos.

\section{A construção de políticas públicas como resultado de embates sociais: uma análise a partir do caso das pessoas com deficiência}

Ao se iniciar o debate acerca das políticas públicas se faz necessário localizá-las no cenário dos projetos societários em disputa, segundo Boneti (2011, p.18) as políticas públicas se constituem no "resultado da dinâmica do jogo de forças que se estabelecem no âmbito das relações de poder, relações essas constituídas pelos grupos econômicos e políticos, classes sociais e demais organizações da sociedade civil". Essas relações incidem diretamente no direcionamento das ações estatais que determinam os rumos de sua intervenção em responder as demandas da realidade social.

Inicialmente, cumpre destacar que, conforme explicam Michael Howlett, M. Ramesh e Anthony Perl (2013), políticas públicas sempre envolvem decisões tomadas por agentes dos Governos. Assim, atividades realizadas por outros atores, tais como organizações não governamentais (ONGs), entidades privadas, indivíduos por si próprios, entre outros, não constituem políticas públicas.

Partindo dessa compreensão, ou seja, de que política pública é, sobretudo, decisão governamental, mostra-se condizente a seguinte definição:

Comumente, o conceito de política pública é definido como as respostas dos governos às demandas, problemas e conflitos que surgem de um grupo social, sendo esse o produto das negociações entre os diferentes interesses, mediado pela racionalidade técnica dos 'fazedores de política', com vistas à manutenção de uma ordem. Nesse entendimento as políticas públicas passam a ser reduzidas a um processo político racional, gerido pelos representantes do Estado (DALFIOR; LIMA; ANDRADE, 2015, p. 213)

Já para Maria das Graças Rua (2009, p. 19), políticas públicas “são uma das resultantes da atividade política [...]: compreendem o conjunto de decisões e ações relativas à alocação imperativa de valores envolvendo bens públicos".

Ante o que se expôs, é possível perceber que as políticas públicas se inserem dentro da atividade política realizada pelo Estado, a partir do reconhecimento de uma demanda social a qual busca-se solucionar, por meio de uma série de ações e decisões, intermediando-se os diferentes interesses envolvidos.

Neste sentido, as políticas públicas não são mera outorga do Estado ou resultado da boa vontade dos governos, mas sem dúvidas, se estabelecem no movimento contraditório da sociedade, no processo de luta pelos direitos a partir da relação entre o Estado e sociedade civil. 
Desse modo, as políticas públicas são "compreendidas como resultado das lutas sociais democráticas e das respostas institucionais produzidas na esfera pública estatal”. (COLIN; SILVEIRA; BONETI, 2016, p. 69)

É possível constar, assim, que há uma lógica dialética de contraposição de forçar e interesses quando se passa a compreender o percurso de elaboração e implementação de políticas públicas, na medida em que se mostra indispensável o acolhimento da problemática por parte dos poderes instituídos, o que, na maioria das vezes, se dá justamente por meio da emergência de segmentos organizados da sociedade civil e dos ambientes de disputa insculpidos.

Assim, embora seja o Poder Público o responsável pela construção e implementação de políticas públicas, não atua de modo isolado, sendo fortemente influenciado pelas organizações da sociedade civil, negócios privados, entre outros atores não governamentais. Desse modo, embora as realizações dos atores não governamentais não constituam, por si só, políticas públicas, colaboram com a construção das mesmas.

Compreendido brevemente a definição de política pública e partindo para a análise do ciclo das políticas, destaca-se que as perspectivas de análise de política a partir das suas etapas de formação desenvolveram-se no período se seguiu após a Segunda Guerra Mundial, contexto em que se aumentaram os estudos visando conferir efetividade às decisões dos governos (BAPTISTA; REZENDE, 2015).

Diversas foram as propostas de ciclo das políticas. Contudo, a concepção que é amplamente divulgada e estudada até hoje é a formulada por Howlett e Ramesh, na década de noventa, os quais previram que o processo de desenvolvimento de uma política pública é composto por cinco fases: “(1) montagem da agenda; (2) formulação da política; (3) tomada de decisão; (4) implementação e (5) avaliação” (BAPTISTA; REZENDE, 2015, p. 226).

Ao se particularizar as políticas públicas para as pessoas com deficiência, essas não podem ser fundamentadas como reparação a uma tragédia pessoal, mas devem ser pautadas na legitimidade das políticas redistributivas, na perspectiva da correção da desigualdade. Assim, as políticas públicas devem incorporar o novo conceito de deficiência "como instrumento de justiça social, e não somente como questão familiar ou individual”. (DINIZ, 2007, p.11)

Nesta lógica, há que se pensar que a falta de bens e serviços ofertados a população deve ser respondida de forma coletiva, no movimento entre Estado e sociedade civil, via políticas públicas que diminuam ou eliminem as restrições de participação e garantam equiparação de oportunidades, a acessibilidade, a inclusão social por meio do reconhecimento dos direitos. (BRASIL, 2011)

Destaca-se que o processo de construção das políticas públicas às pessoas com deficiência é direcionado a partir de parâmetros, fruto de lutas coletivas que se materializaram em legislações, programas, serviços e benefícios que visam a inclusão social, o respeito à dignidade, o combate ao preconceito e a valorização das diferenças. Vale destacar que este é um processo em construção que encontra maior efetividade a medida em que a sociedade civil organizada, respeitando o direito de "fala" das pessoas com deficiência, incidem neste movimento de luta pelo reconhecimento dos direitos.

Em um recorte histórico pode-se afirmar que até o início do século XX havia poucos marcos legais destinados às pessoas com deficiência, apenas ações restritas ao campo ensino aprendizagem. No Brasil, somente em 1961 estabeleceu-se a Lei de Diretrizes e Bases da Educação indicando o atendimento educacional na modalidade educação especial para as pessoas com deficiência entendidas à época como “excepcionais”. Destaca-se, conforme já mencionado, que um marco 
mundial foi a proclamação do "Ano Mundial das Pessoas Deficientes" em 1981 pela ONU indicando a necessidade de promover direitos a essa população. (PARANA, 2017a)

A Constituição Brasileira de 1988 assegurou o direito das pessoas com deficiência acessarem a educação básica, preferencialmente na rede regular de ensino, isso como dever do Estado. Em 1993 foi instituído o Benefício de Prestação Continuada (BPC) a partir da Lei Orgânica de Assistência Social (LOAS) Lei 8742/93, como o objetivo de proteger os idosos e as pessoas com deficiência, devido as vulnerabilidades apresentadas. O BPC consiste no acesso a um salário mínimo nacional aos idosos com 65 anos ou mais, e pessoas com deficiência de qualquer idade, com critério de renda per capta familiar de $1 / 4$ do salário mínimo, como direito a proteção social. (COSTA, 2014). Em 1996 passou a vigorar a nova Lei de Diretrizes e Bases da Educação (LDB) apresentando parâmetros para a educação especial, preconizando o ensino regular.

No campo internacional houve importantes avanços no campo das legislações como, por exemplo, a Declaração de Salamanca de 1994 com princípios e diretrizes sobre o atendimento educacional, além de orientações para que o poder público implementasse ações voltadas as pessoas com deficiência. Outro marco foi a Convenção da Guatemala de 1999 ratificada pelo Brasil pelo Decreto 3.956/2001 que assegurou às pessoas com deficiência os mesmos direitos humanos e liberdades fundamentais que as demais pessoas. Além do grande marco legal, a Convenção Internacional sobre os Direitos das Pessoas com deficiência da ONU de 2006, já mencionada neste artigo, foi ratifica no Brasil como emenda constitucional em 2009, bem como seu Protocolo Facultativo, a fim de defender e garantir a dignidade das Pessoas com deficiência (PARANA, 2017 ${ }^{\text {a). }}$

No âmbito nacional, em 2002 a Língua Brasileira de Sinais (LIBRAS) foi reconhecida oficialmente como uma língua, como um meio de comunicação pela Lei 10.436/2002, com protagonismo da comunidade surda. A partir do Decreto 5.296/2004 passou-se a discutir as normas e critérios básicos para a promoção da acessibilidade às pessoas com deficiência e com mobilidade reduzida. Em 2011, o governo federal lançou o Plano Nacional dos Direitos da Pessoa com Deficiência - Viver sem Limites, como o objetivo de implementar os parâmetros da Convenção da ONU por meio de políticas públicas. Em 07 de janeiro de 2015 a Lei 18.419 instituiu o Estatuto da Pessoa com Deficiência do Estado do Paraná. E em 06 de julho de 2015 o documento nacional, a Lei Brasileira de Inclusão (LBI) nำ13.146 conhecida como Estatuto da Pessoa com Deficiência entrou em vigor (PARANA, 2017a).

O Estatuto estabelece um conjunto de direitos que devem ser garantidos às Pessoas com deficiência, a partir de sua essência, à igualdade de oportunidades e o combate a todas as formas de discriminação. A LBI garante a proteção dos direitos individuais e dos direitos coletivos como: direito à vida, a saúde, habilitação e reabilitação, educação, moradia, ao trabalho, à assistência social, a cultura, ao esporte, turismo e lazer, direito ao transporte e a mobilidade, acessibilidade, a informação e a comunicação, a tecnologia assistiva, direito a justiça e a participação na vida pública e política. (BRASIL, 2015). Todos esses direitos foram embasados a partir do conceito de deficiência apresentado pela Convenção da ONU considerando as suas especificidades, nessa lógica o desafio se dá na sua implementação.

Observa-se, também, no campo das políticas públicas alguns benefícios destinados às pessoas com deficiência: o BPC, já mencionado no texto, os benefícios de isenção tarifária de transportes, benefícios de meia entrada em eventos culturais e esportivos, isenção de alguns impostos na compra de veículos a partir do entendimento da necessidade de adaptação do veículo, desconto na compra de passagens aéreas, entre outros. Vale ressaltar que os benefícios são direitos que buscam a igualdade de oportunidades. 
Na perspectiva apresentada sobre a construção das políticas públicas como um movimento das disputas de interesses na sociedade, apresentam-se os mecanismos de participação e controle social, como, por exemplo, os Conselhos de Direitos. Garantidos constitucionalmente, os conselhos são espaços colegiados de acompanhamento, avaliação, consulta ou deliberação das políticas públicas, estão presentes nas três esferas de poder, no âmbito federal (Conselho Nacional), nos entes federados (Conselhos Estaduais) e no âmbito municipal (Conselhos Municipais) de cada política pública. Respeitando os parâmetros legais para a sua criação e funcionamento.

No campo da Pessoa com deficiência existe o CONADE (Conselho Nacional dos Direitos da Pessoa com Deficiência), criado em 1999 pelo Decreto 3.298, no Estado do Paraná o COEDE (Conselho Estadual dos Direitos da Pessoa com Deficiência) criado em 2002 pela Lei 13.456 de 2002 e inscrito no Estatuto estadual em 2015. Em relação aos conselhos municipais, no Estado do Paraná até o ano de 2017 havia 97 conselhos em funcionamento (PARANA, 2017b), considerando que o Estado é composto por 399 municípios. Portanto, a expansão desses mecanismos de participação é um desafio a ser enfrentado. Vale destacar que o Plano dos Direitos da Pessoa com deficiência do Estado do Paraná (2018-2021), aprovado em 2017 tem em uma de suas metas a ampliação da implantação dos conselhos municipais da Pessoa com deficiência.

Pensar em políticas públicas significa reconhecer a sua legitimidade a partir da defesa dos direitos que assegurem garantias que possibilitem a correção das disparidades, efeitos de uma sociedade estruturalmente desigual. Assim, no movimento das contradições, na relação entre Estado e sociedade civil organizada, por meio de seus diversos sujeitos coletivos, entre as forças sociais e as respostas institucionais que as políticas públicas se estabelecem.

Destaca-se que historicamente as políticas públicas para as pessoas com deficiência foram concebidas pelo viés biomédico da deficiência, ou seja, considerando a patologia corporal, o desafio, no entanto, é repensar esse modelo a partir do modelo social da deficiência em que busca-se a integralidade da pessoa com deficiência reconhecendo-a como sujeito de relações sociais. As disputas desses dois modelos serão apresentadas a seguir.

\section{A dialeticidade de um debate: a concepção de deficiência entre o modelo biomédico e o modelo social}

Este item apresenta as concepções do modelo biomédico e do modelo social da deficiência, na perspectiva dos projetos societários em disputa nesse embate dialético.

Neste sentido, apresentam-se as características de cada modelo a partir da perspectiva crítica na direção do reconhecimento das pessoas com deficiência enquanto sujeitos sociais de direitos.

O modelo biomédico considera a deficiência sendo a lesão em um corpo, como responsabilidade individual, os impedimentos devem ser objeto de intervenção médica com práticas de reabilitação a fim de atenuar a anormalidade. Pensar nesta concepção de atuação com as pessoas com deficiência, refletindo também para além do atendimento médico as formas educacionais que buscam a "docilização" dos corpos para que se adaptem ao padrão social de aceitação. (DINIZ; BARBOSA; SANTOS, 2009)

O modelo médico da deficiência insere-a no campo das doenças, do problema individual, da anormalidade que precisam ser enfrentadas, transitando entre a tragédia individual e a necessidade de reabilitação com a finalidade de produtividade, em detrimento do reconhecimento de políticas sociais de proteção social que visem reparação da desigualdade vivenciada. (DINIZ, 2007) 
Essa abordagem apresenta uma concepção de deficiência restrita ao indivíduo e limitada a patologia corporal, a deficiência é entendida como doença, uma anormalidade, sendo necessário a busca de meios de reabilitação como forma de integrar as pessoas ao padrão de normalidade imposto pela sociedade, visto que as pessoas são valoradas pelo que elas produzem e não por quem elas são. Daí a necessidade de outra concepção de deficiência que considere não só o sujeito em suas particularidades, mas no processo de interação com a sociedade na perspectiva da desigualdade de oportunidades.

A discussão sobre a deficiência para além do modelo médico surgiu na Inglaterra e nos Estados Unidos por volta da década de 1970, entendendo que não era possível compreender a deficiência apenas como lesão corporal, mas era necessário considerar as restrições de participação das pessoas. Desse modo, entende-se que a "deficiência é um conceito complexo que reconhece o corpo com lesão, mas que também denuncia a estrutura social que oprime a pessoa deficiente". (DINIZ, 2007, p.9)

No modelo social há uma percepção de que a deficiência é causada também pelo ambiente em que a pessoa está inserida, como, por exemplo, caso das pessoas institucionalizadas para a reabilitação que tiveram agravado seu grau de deficiência. Discutir a deficiência para além da característica corporal, do campo das doenças é a grande revolução do modelo social. (DINIZ, 2007).

Vale destacar que os modelos médico e social são concepções em disputa que determinam o entendimento do que é deficiência e influenciam diretamente nos rumos das políticas públicas diante da cultura da normalidade.

Quando se expressa à discussão do modelo social é preciso reconhecer também que houve avanços médicos que proporcionaram bem estar e qualidade de vida das pessoas com deficiência. No entanto, a centralidade desta concepção incide em reconhecer o processo de desigualdade vivenciada pelas pessoas com deficiência, no sentido de que "quanto maiores forem às barreiras sociais, maiores serão as restrições de participação impostas aos indivíduos com impedimentos corporais". (DINIZ; BARBOSA; SANTOS, 2009, p.67)

O modelo social é uma crítica ao sistema de produção e reprodução capitalista em que as pessoas são definidas por suas "capacidades" e produtividade.

$\mathrm{Na}$ concepção social diferenciam-se os impedimentos intelectuais, físicos e sensoriais da opressão da deficiência, conforme afirma Diniz (2007), a opressão advém da cultura da normalidade que agrava as barreiras sociais, sendo assim a pessoa pode ter impedimentos corporais e não vivenciar a opressão. Assim, a luta pelo reconhecimento da diversidade e valorização da diferença é um caminho que vem ao encontro do modelo social da deficiência.

Segundo França (2013), a legitimidade do modelo social implica discutir essencialmente duas abordagens: cultural e materialista. Na primeira entende-se que a opressão e o preconceito não se caracterizam apenas pela discriminação material, mas também pelas representações culturais. A segunda abordagem compreende que a opressão vivenciada pelas pessoas com deficiência é o resultado da dinâmica do sistema capitalista. Portanto, seu enfrentamento estaria centrado na luta de classes no cenário das disputas societárias. Vale destacar que as duas abordagens não são contrárias, mas complementares, assim, trazem maior consistência à necessidade do modelo social da deficiência.

Destaca-se que segundo a Organização Mundial da Saúde (OMS) as deficiências podem ser classificadas de duas formas: a Classificação Internacional de Doenças (CID-10) e a Classificação Internacional de Funcionalidade, Deficiência e Saúde (CIF). A primeira classificação está vinculada ao modelo biomédico de diagnóstico de deficiência como patologia, doença e anormalidade 
geradoras de impedimentos corporais. Este modelo por um longo tempo teve hegemonia no diagnóstico das deficiências, assim grande parte das políticas públicas estão enraizadas neste viés. Em 2001 a CIF é aprovada, antecipando os princípios consagrados na Convenção Internacional sobre os Direitos da Pessoa com deficiência de 2006, considerando critérios de mensuração das barreiras e restrições de participação, princípios vinculadas diretamente ao modelo social da deficiência (DINIZ; BARBOSA; SANTOS, 2009).

Assim, a partir da participação dos movimentos sociais, instituições acadêmicas e intenso debate político a CIF foi construída. Desse modo, a deficiência sai do campo das doenças e suas consequências e passa a ser compreendida sob outros aspectos com centralidade na interação entre a pessoa e a sociedade. (DINIZ, 2007).

A CIF se constituiu em um vocabulário biopsicossocial que descreve os impedimentos corporais, as barreiras sociais e a participação isso significa que é necessário reconhecer a desigualdade pela deficiência.

As disputas dos modelos biomédico e social não se dão apenas como perspectiva metodológica de análise da deficiência, elas representam concepções de quem é a pessoa com deficiência, do seu lugar social, quais direitos devem acessar, além da distância entre um modelo e outro da compreensão da gênese da desigualdade social. Portanto, após essa explanação mais generalista, o artigo apresentará no item a seguir a concepção biopsicossocial inscrita na Lei Brasileira de Inclusão (LBI) - Estatuto da Pessoa com Deficiência de 2015.

\section{A síntese prática do debate conceitual e a concepção biopsicossocial da lei brasileira de inclusão (lbi)}

A Lei Brasileira de Inclusão (LBI) de 2015 é o marco legal de defesa e promoção dos direitos e das liberdades fundamentais das pessoas com deficiência, na perspectiva da igualdade de condições com as demais pessoas visando à inclusão social. Foi elaborada a partir do conceito de deficiência inscrito na Convenção Internacional sobre os Direitos das Pessoas com Deficiência de 2006 da Organização das Nações Unidas (BRASIL, 2015).

Esta normativa se apresenta na centralidade da discussão sobre a insuficiência do modelo biomédico justificando, assim, a necessidade do avanço do modelo social da deficiência. Sabe-se que a luta pelo reconhecimento do modelo social desencadeou a criação da Classificação Internacional de Funcionalidade, Deficiência e Saúde (CIF) que subsidia a perspectiva biopsicossocial da LBI, fortalecendo assim, a concepção ampliada de deficiência.

Evidencia-se, então, a discussão apresentada sobre as políticas públicas, bem como, suas previsões legais, as legislações, estas como construções sociais a partir das disputas de interesses, cenário também da organização da sociedade civil. Neste contexto foi inscrita a Lei Brasileira de Inclusão (LBI), estabelecendo-se no campo da organização e incidência política, com destaque a um processo gradativo de conquistas apresentado a seguir, que ensejaram na concepção biopsicossocial prevista nesta normativa.

Segundo Santos (2016), na particularidade brasileira, em 2007 foram adotados pelo INSS os parâmetros da CIF para avaliar a concessão do Benefício de Prestação Continuada (BPC). Em 2013 foi a vez de a Previdência Social incorporar essa classificação para avaliação das pessoas com deficiência no momento da solicitação de aposentadoria, tendo as barreiras como elementos centrais para avaliação como restrição da participação social. 
Assim, foi criado Índice de Funcionalidade Brasileiro (IFBr) com a intenção de aplicá-lo em todas as políticas públicas destinadas às pessoas com deficiência. Esse instrumental:

[...] é composto por 41 Atividades e Participação de acordo com a CIF, além de contar com uma métrica para pontuação das Atividades de acordo com a Medida de Independência Funcional - MIF15. A MIF gradua a realização das atividades a partir de uma avaliação da situação de dependência da pessoa para realizá-las. (SANTOS, 2016, p.3011)

A partir da incorporação do conceito de deficiência da Convenção da ONU a Previdência Social passou a utilizar esse parâmetro para as aposentarias por tempo de contribuição ou por idade para as pessoas com deficiência. Assim, a partir dessa avaliação é possível caracterizar os graus de deficiência como: leve, moderado ou grave o que possibilita a diminuição de dois, seis ou dez anos de contribuição em relação às pessoas sem deficiência. Esta análise se dá por meio do perito médico e da avaliação social baseada na CIF realizada por assistentes sociais, onde ambos utilizam o mesmo instrumental identificando as 41 Atividades e Participação da CIF expressas no IFBr (SANTOS, 2016).

Isso demonstra um importante avanço nas políticas públicas por meio da concepção biopsicossocial. O desafio posto é a necessidade de sua ampliação para as demais políticas públicas, e também do aperfeiçoamento de instrumentais que possibilitem a mensuração das diversas barreiras e impedimentos descritos na LBI, que é fruto de uma sociedade estruturalmente desigual, gênese do sistema capitalista, o que legitima a necessidade do modelo social incidindo assim, na concepção de deficiência.

Portanto, nesta perspectiva a deficiência está inserida no campo dos impedimentos corpóreos em relação à interação com as barreiras que obstruem a participação plena e efetiva na sociedade, em igualdade de condições com as demais pessoas, conceito apresentado no artigo $2^{\circ}$ da LBI.

Esse mesmo artigo apresenta o parâmetro de avaliação da deficiência, quando necessária, deve ser realizada a partir do modelo biopsicossocial, por meio de equipe multidisciplinar e interdisciplinar, considerando os seguintes fatores: os impedimentos nas funções e nas estruturas do corpo; os fatores socioambientais, psicológicos e pessoais; a limitação no desempenho de atividades; e a restrição de participação. (BRASIL, 2015)

Neste sentido, faz-se necessário pensar na avaliação biopsicossocial por meio do trabalho multidisciplinar na perspectiva de uma atuação interdisciplinar, isso significa considerar os desafios da construção coletiva buscando romper com a fragmentação do conhecimento e da práxis. A atuação multidisciplinar se dá na realização de atividades por meio de parceria de diferentes áreas, já a interdisciplinaridade se estabelece no olhar das diferentes disciplinas sobre um mesmo objetivo que ao ser alcançado gera um novo saber. Segundo Carvalho (2012), a interdisciplinaridade se efetiva quando se tem a consciência que uma profissão não está isolada de outras, além disso, é necessário que haja interação entre as mesmas, isto é, a troca de diferentes saberes.

Na sequência, o terceiro artigo da LBI apresenta os parâmetros fundamentais para que haja efetivação desta lei, assim, considera-se a necessidade da: promoção da acessibilidade no sentido amplo (espaços, mobiliários, equipamentos, transportes, comunicação, etc.), como forma de possibilitar a autonomia às pessoas com deficiência; o desenho universal para produtos, ambientes, programas e serviços; tecnologia assistiva que promovam funcionalidade na perspectiva da inclusão social; considerando as barreiras à participação social da pessoa, como obstáculos 
que cerceiam seus direitos e liberdades fundamentais. Para esse efeito são consideradas as barreiras urbanísticas, arquitetônicas, barreiras nos transportes, barreiras nas comunicações e na informação, barreiras atitudinais e tecnológicas (BRASIL, 2015).

Ainda, em relação ao artigo supracitado destaca-se a necessidade do desenvolvimento da comunicação abrangente a todas as pessoas com deficiências, considerando também as suas particularidades, como, por exemplo, o uso da Libras, do Braille, sistemas auditivos, entre outros; a promoção de adaptações razoáveis para assegurar a igualdade de condições; as obras de urbanização devem garantir acesso aos serviços de forma adequada, bem como o mobiliário urbano, ou seja, objetos existentes nos espaços públicos devem ser devidamente sinalizados respeitando as regras de acessibilidade; destacando ainda, a necessidade de implementação de serviços destinados as pessoas com deficiência, como as residências inclusivas (serviço tipificado pela Assistência Social), moradias que visem vida independente como, por exemplo, os condomínios sociais; a garantia de profissional de apoio escolar em todas as atividades que forem necessárias; e a garantia de acompanhante (BRASIL, 2015).

Ainda, nesta mesma perspectiva da construção de parâmetros para as políticas públicas, se apresenta o Cadastro Nacional de Inclusão da Pessoa com Deficiência (Cadastro-Inclusão) previsto no artigo 92 da Lei Brasileira de Inclusão de 2015. O texto da Lei discorre sobre a necessidade da criação de um sistema de informação com dados estatísticos, realidade socioeconômica, barreiras enfrentadas pelas pessoas com deficiência nos territórios que impedem o exercício de seus direitos, subsídios para a formulação, gestão, monitoramento e avaliação das políticas públicas a este grupo populacional. (BRASIL, 2015)

Esse registro público de coleta, processamento, sistematização e disseminação de informações será uma importante ferramenta para a implementação de políticas públicas a partir da realidade de desigualdade dos diferentes territórios no país. 0 texto está escrito no futuro porque este cadastro ainda está em fase de estudo desde o ano de 2015, sem grandes avanços devido às mudanças da conjuntura política dos últimos anos.

Todos esses elementos citados anteriormente compõem o rol de recomendações que devem ser consideradas para eliminar a restrição da participação social das pessoas com deficiência.

Ao mesmo tempo, a partir dessas considerações se estabelece o conceito biopsicossocial da deficiência considerando para além das patologias corporais os fatores sociais, ambientais, psicológicos e pessoais. Assim, amplia-se o entendimento de que a deficiência não está presa ao corpo, mas se expressa nas barreiras e impedimentos que restringem a plena participação das pessoas na sociedade em igualdade de condições.

Neste processo, a discussão apresentada no artigo consiste em demarcar a importância do modelo biopsicossocial da deficiência nas políticas públicas a partir da restrição da participação social, significa ir para além do modelo biomédico e reconhecer a deficiência como reflexo da desigualdade social.

Nesse sentido, o desafio se encontra em como mensurar as barreiras que impedem a plena participação das pessoas com deficiência na sociedade, ao mesmo tempo, o debate tem uma intencionalidade de refletir sobre a aplicabilidade do modelo biopsicossocial nas políticas públicas sob a perspectiva do respeito e da valorização da diversidade humana.

Assim, as políticas públicas destinadas às pessoas com deficiência devem romper com a ideia individualizada de restrição e trazer o debate da opressão social, elemento fundamental para pensar o modelo social da deficiência. Nesse sentido, considera-se a deficiência a partir 
das barreiras produzidas pela forma de organização da sociedade, pelos valores culturais que perpassam o conceito de deficiência (MARTINS, 2005).

Nesta perspectiva, a compreensão de todo o processo histórico de opressão, segregação, discriminação e naturalização da violação de direitos das pessoas com deficiência devem ser sempre considerados como substrato da criação das políticas públicas fundamentadas na luta pela inclusão no sentido de emancipação dos sujeitos. Conforme descreve Fonseca (2012, p.51):

É possível sintetizar o processo histórico em distintos momentos que se caracterizam, respectivamente, por uma primeira fase de extermínio das pessoas com deficiência, seguida pela exclusão caritativa e cultural, até a fase contemporânea, iniciada no século XIX, que se subdivide em integração instrumental, inclusão, e, por fim, emancipação.

Sabe-se que as políticas públicas surgem como um movimento de resposta às lutas sociais, e se fundamentam no reconhecimento da desigualdade social, o que legitima as lutas pelos direitos humanos que devem ser respondidos pelo Estado por meio de legislações e políticas transversais e setoriais em vistas da garantia de direitos. Nesse cenário, as políticas públicas se apresentam no contexto do abismo da desigualdade social, fruto do modelo econômico vigente das suas estratégias e ressignificações. Assim, pensar nas políticas públicas significa criar condições para que as pessoas possam acessá-las, perpassando pela intersetorialidade e transversalidade a partir do território na perspectiva da totalidade, com um importante papel da sociedade civil organizada (SPOSATI, 2011).

No debate das políticas públicas na perspectiva das disputas de interesses, se faz necessário evidenciar a seguinte indagação apresentada por Martins (2005, p.15), "será que as políticas sociais se vêm desenvolvendo no seio de uma abordagem dominante da deficiência, uma abordagem que há muito vem informando a perpetuação da desigualdade social?". Essa questão deve ocupar a centralidade e perpassar todo o processo de elaboração e efetivação das políticas públicas para as pessoas com deficiência.

É preciso reconhecer que as políticas sociais voltadas às pessoas com deficiência tendem a perspectiva residual de naturalização da exclusão social quando a visão de deficiência persiste a reafirmação do conceito da anormalidade corpórea e incapacidade funcional. Essa ideia advinda do modelo biomédico permanece no imaginário das pessoas deixando às limitações na centralidade da deficiência invisibilizando as barreiras produzidas socialmente (MARTINS, 2005).

Ao se particularizar as políticas públicas destinadas às pessoas com deficiência torna-se imprescindível então, a reflexão das categorias: barreiras, impedimentos, participação e igualdade de condições, elementos da desigualdade estrutural inerente ao sistema capitalista. Assim, neste cenário, para que as políticas públicas possam proporcionar respostas mais eficientes, a sua essência deve estar respaldada no reconhecimento da desigualdade social que se expressa na restrição de acesso e oportunidades que o público destinatário das políticas públicas vivencia na sociedade. É neste princípio que se reafirma a importância das políticas públicas como forma de redução da desigualdade.

Portanto, faz-se necessário criar instrumentos que visem à prevenção da violação de seus direitos humanos, reconhecendo a importância de sua autonomia, inclusive na participação da formulação das políticas públicas que devem ter em sua essência a defesa e a proteção da dignidade das pessoas com deficiência. A luta se respalda na defesa da inclusão na sociedade, o respeito às 
diferenças, por meio da valorização da diversidade humana, pela construção da acessibilidade e de igualdade de oportunidades (BRASIL, 2008).

Destaca-se que a compreensão da deficiência enquanto questão social é algo recente. Historicamente o entendimento da deficiência foi construído pela medicina como patologia de cunho individual ligado a tragédia pessoal.

Desse modo, com a prevalência da concepção biomédica, as barreiras e impedimentos tendem a serem naturalizadas vinculando as limitações funcionais, concebendo as pessoas com deficiência como sujeitos passivos e dependentes de cuidados. Sendo assim, a partir do reconhecimento dos limites do modelo médico e com a incorporação do contexto sociopolítico da deficiência, emergiu o modelo social da deficiência, reconceituando-a como opressão social. Abriu-se então, uma nova perspectiva para formulação das políticas públicas para este segmento (MARTINS et al., 2012).

Para que as políticas públicas tenham maior impacto se faz necessária uma consciência pela coletivização das demandas rompendo com a lógica individualizada, própria do sistema econômico vigente. É preciso reconhecer que "a exploração capitalista não se dá somente na fábrica, no mundo das ações e investimentos, mas, também, nos mais diversos espaço-tempo e setores da vida social e cultural. E com isso, realizam uma inflexão na sua forma de exigir e lutar por direitos" (GOMES, 2017, p.10).

No caso das pessoas com deficiência há ainda um grande desafio que precisa ser enfrentado nesse processo, a concretização da representatividade em que "os sujeitos dessas políticas pudessem ser não somente os seus destinatários, mas, principalmente, sujeitos na construção da agenda e na formulação dessas mesmas políticas". (GOMES, 2017, p.14). Significa construir com os sujeitos e não apenas para os sujeitos, evidencia-se então, a necessidade da qualificação da participação social com protagonismo das pessoas com deficiência, as quais devem ocupar o seu lugar de fala e de incidência.

Ressalta-se que o modelo biopsicossocial preconizado na LBI apresenta os parâmetros para a elaboração das políticas públicas, a partir do modelo social da deficiência considerando a insuficiência do modelo biomédico e a desigualdade imposta as pessoas com deficiência. Assim, cabe avançar na construção de políticas públicas embasadas a partir dessa ótica, bem como efetivar mecanismos que propiciem a aplicabilidade do modelo biopsicossocial nas políticas públicas para as pessoas com deficiência, o Cadastro Nacional de Inclusão da Pessoa com Deficiência (CadastroInclusão) é um exemplo apresentado nesse artigo.

Neste sentido, vale destacar que as políticas públicas são construídas no cenário das disputas de interesses na relação Estado e sociedade civil em meio a teia do jogo político entre os interesses econômicos, as forças sociais e ações governamentais. Sendo assim, é neste contexto que se inscrevem as disputas não só por políticas públicas, mas pelas concepções de políticas públicas, no caso desta pesquisa, da disputa entre o modelo biomédico e o modelo biopsicossocial da deficiência. Este último está em consonância com a luta pela inclusão social da pessoa com deficiência, reconhecendo o valor das diferenças e preservando a igualdade de direitos.

\section{Conclusão}

A luta pelos direitos das pessoas com deficiência é forjada no movimento das contradições societárias. Tais contradições ganham ainda mais notoriedade quando tratadas a partir de agrupamentos sociais que historicamente encontraram-se às margens da sociedade brasileira. 
Desta forma, analisar as concepções acerca da deficiência requer uma abordagem crítica, a fim de desconstruir o objeto em si até que se chegue ao seu abstrato, para posteriormente reconstruí-lo demonstrando as contradições nele existentes. Nesse aspecto, foi preciso se compreender os passos - por vezes lentos - que levaram a tutela e ao reconhecimento da pessoa com deficiência enquanto um ator político, jurídico e social no país.

Assim, reconhecendo-se o pressuposto de que a dialética parte do abstrato ao concreto, bem como de uma exposição crítica da realidade, pretendeu-se, a partir do método aduzido, apresentar uma reflexão que debatesse os vieses por vezes existentes nas próprias concepções oficiais acerca da deficiência e de sua construção social.

Qualquer fenômeno é descrito como a coisa que se manifesta imediatamente, mas que oculta sua essência que é, de fato, a realidade. Assim se apresentou o presente estudo. Portanto, foi necessário se decompor conceitos a fim de atingir o conhecimento, que se apresenta como a decomposição do todo para atingir o mundo real. Este mundo real nada mais é do que a práxis humana, tendo o homem papel fundamental, especialmente em suas revoluções sociais. Tal processo foi descrito por meio da indicação das políticas públicas pensadas e empreendidas para a pessoa com deficiência.

Desta feita, ressurgiu a necessidade de afirmar um conceito de deficiência que não se restrinja as patologias corporais, mas que considere a desigualdade social expressa nas diferentes barreiras e impedimentos vivenciados pelas pessoas com deficiência torna-se imprescindível.

Reconhecer então, que as políticas públicas são fruto das lutas sociais e das disputas de interesses, e na particularidade da pessoa com deficiência implica inseri-la em um papel de participante desse processo em construção.

Desse modo, significa romper com os diagnósticos médicos que decretam a incapacidade da pessoa com deficiência e construir uma nova abordagem que vise à busca de autonomia, o reconhecimento e a valorização das diferenças como um dado natural da diversidade humana, na perspectiva da inclusão social. Nesse sentido, o modelo biopsicossocial não se restringe a uma forma de análise para enquadramento e concessão de benefícios, mas é uma concepção de política pública que reconhece a pessoa com deficiência enquanto sujeito de direitos em sua totalidade.

Por fim, é imperioso se reconhecer que o debate ora apresentado não se esgota nos limites propostos, especialmente ao se reconhecer que a atual conjuntura do país mostra-se refratária ao pleno desenvolvimento da pessoa em sua subjetividade, notadamente dos grupos que encontram-se de algum forma em situação de vulnerabilidade social.

Com isso, a sensação final é de necessidade de novos e constantes análises sobre o desenvolvimento de políticas e discursos oficiais presentes no seio da sociedade brasileira, de forma a se monitorar a permanência ou desconstrução dos avanços ora apresentados.

\section{Referências}

BAPTISTA, Tatiana Wargas de Faria; REZENDE, Mônica de. A ideia de ciclo na análise de políticas públicas. In: MATTOS, Ruben Araujo de; BAPTISTA, Tatiana Wargas de Faria (org.). Caminhos para Análise das Políticas de Saúde. 1. ed. Porto Alegre: Rede UNIDA, 2015. p. 221-260.

BONETI, Lindomar. Políticas públicas por dentro. 3.ed. Ijuí: UNIJUÍ, 2011.

BRASIL. Convenção sobre os Direitos das Pessoas com Deficiência: Protocolo Facultativo à Convenção sobre os Direitos das Pessoas com Deficiência: decreto legislativo $n^{\circ}$ 186, de 09 de julho 
de 2008: decreto no 6.949, de 25 de agosto de 2009. 4.ed., rev. e atual. - Brasília: Secretaria de Direitos Humanos, Secretaria Nacional de Promoção dos Direitos da Pessoa com Deficiência, 2011.

BRASIL. A Convenção sobre Direitos das Pessoas com Deficiência Comentada /Coordenação de Ana Paula Crosara Resende e Flavia Maria de Paiva Vital. Brasília: Secretaria Especial dos Direitos Humanos. Coordenadoria Nacional para Integração da Pessoa Portadora de Deficiência, 2008.

BRASIL. Lei no 13.146, de 06 de julho de 2015. Institui a Lei Brasileira de Inclusão da Pessoa com Deficiência (Estatuto da Pessoa com Deficiência). Brasília, 2015. Disponível em: <http://www. planalto.gov.br/ccivil_03/_Ato2015-2018/2015/Lei/L13146.htm>. Acesso em 05 dez. 2018.

CARVALHO, Fabiana Aparecida. O Serviço Social e a interdisciplinaridade. Revista Diálogos, vol.18, p.74-79, 2012. Disponível em: <http://www.proceedings.scielo.br/pdf/cips/n4v1/27.pdf>. Acesso em 20 nov. 2018.

COLIN, Denise Arruda; SILVEIRA, Jucimeri Isolda; BONETI, Lindomar. Políticas públicas e Direitos Humanos: crítica aos fundamentos epistemológicos e a incidência dos sujeitos coletivos. In: Cezar Bueno de Lima, Mirian Célia Castellain Guebert. (Org.). Teorias dos direitos humanos em perspectiva interdisciplinar. 3ed. Curitiba: PUCPRess, 2016.

CONVENÇÃO DE VIENA. Conferência Mundial de Viena sobre Direitos Humanos de junho de 1993. Disponível em: < http://www.dhnet.org.br/direitos/anthist/viena/viena.html>. Acesso em: 07 nov. 2018.

COSTA, Lucia Cortes. Gestão dos Benefícios Sócio Assistenciais. Ponta Grossa: UEPG/NUTEAD, 2014.

DALFIOR, Eduardo Tonole; LIMA, Rita de Cássia Duarte; ANDRADE, Maria Angélica Carvalho. Reflexões sobre análise de implementação de políticas de saúde. Saúde em Debate, Rio de Janeiro, v. 39, n. 104, p. 210-225, mar. 2015. Disponível em: http://www.scielo.br/pdf/sdeb/v39n104/0103-1104sdeb-39-104-00210.pdf. Acesso em: 25 jul. 2019.

DINIZ, Debora. O que é deficiência. São Paulo: Brasiliense, 2007.

DINIZ, Debora; BARBOSA, Lívia; SANTOS; Wederson Rufino dos. Deficiência, direitos humanos e justiça. Revista Internacional de Direitos Humanos, São Paulo, v. 6, n. 11, p. 65-77, dez. 2009.

FONSECA, Ricardo Tadeu Marques. O novo conceito constitucional de Pessoa com deficiência: um ato de coragem. Revista TRT da $2^{\underline{0}}$ Região, São Paulo, nº 10, p.45-54, 2012

FRANÇA, Tiago Henrique P. M. Modelo Social da Deficiência: uma ferramenta sociológica para a emancipação social. Lutas Sociais (PUCSP), v. 17, p. 59-73, 2013.

GOMES, Nilma Lino. Políticas Públicas para a diversidade. Sapere Aude: Revista de Filosofia, v. 8, p. 7-22, 2017.

HOWLETT, Michael; RAMESH, M.; PERL, Anthony. Política Pública: seus ciclos e subsistemas. Tradução de Francisco G. Heidemann. 3. ed. Rio de Janeiro: Elsevier, 2013.

MARTINS, Bruno Daniel Gomes de Sena. Políticas sociais na deficiência: Exclusões perpetuadas. Centro de Estudos Sociais, p.1-19, 2005.

MARTINS, Bruno Daniel Gomes de Sena; FONTES, Fernando; HESPANHA, Pedro; BERG, Aleksandra. A emancipação dos estudos da deficiência. Revista Crítica de Ciências Sociais. Coimbra, n.98, p.45-64, 2012. 
ORGANIZAÇÃO DAS NAÇÕES UNIDAS (ONU). Convenção sobre os direitos das pessoas com deficiência. Disponível em:<www.un.org/ruleoflaw/blog/document/convention-on-the-rights-ofpersons-with-disabilities/ >. Acesso em: 06 nov. 2018.

PARANÁ. Conhecendo a Pessoa com deficiência. Coleção Paraná Incluso, vol. 1. 2016

PARANÁ. Conhecendo a Pessoa com deficiência. Coleção Paraná Incluso, vol. 2. 2017.

PARANÁ. Guia de criação dos Conselhos Municipais dos Direitos da Pessoa com deficiência. 2017.

PARANÁ. Plano dos direitos da pessoa com deficiência do Estado do Paraná. Autores: Ana Paula dos Santos e Tamara Zazera Rezende. Curitiba: Secretaria de Estado da Família e Desenvolvimento Social, 2017.

RUA, Maria das Graças. Políticas Públicas. Florianópolis: Departamento de Ciências da Administração / UFSC; Brasília: CAPES: UAB, 2009.

SANTOS, Wederson. Deficiência como restrição de participação social: desafios para avaliação a partir da Lei Brasileira de Inclusão. Ciência \& Saúde Coletiva (Online), v. 21, p. 3007-3015, 2016.

SASSAKI, Romeu Kazumi. Como chamar as pessoas que têm deficiência. In: SASSAKI, R.K. Vida independente; História, movimento, liderança, conceito, filosofia e fundamentos. São Paulo: RNR, 2003.

SASSAKI, Romeu Kazumi. Terminologia sobre deficiência na era da inclusão. Revista Nacional de Reabilitação, São Paulo, v.5, n.25, mar.-abr. p.5-14. 2002.

SPOSATI, Adaíza. Tendências latino-americanas da política social pública no século 21. R. Katál., Florianópolis, v. 14, n. 1, p. 104-115, jan./jun. 2011. Disponível em: <https://periodicos.ufsc.br/index. php/katalysis/article/view/S1414-49802011000100013/177 45>. Acesso em: 20 nov. 2018. 